Portland State University

PDXScholar

Civil and Environmental Engineering Faculty

Publications and Presentations

$12-17-2018$

\title{
Lifecycle Modeling and Assessment of Unmanned Aerial Vehicles (Drones) CO2e Emissions
}

Miguel A. Figliozzi

Portland State University

Follow this and additional works at: https://pdxscholar.library.pdx.edu/cengin_fac

Part of the Civil and Environmental Engineering Commons

Let us know how access to this document benefits you.

\section{Citation Details}

Figliozzi, Miguel A., "Lifecycle Modeling and Assessment of Unmanned Aerial Vehicles (Drones) CO2e Emissions" (2018). Civil and Environmental Engineering Faculty Publications and Presentations. 419. https://pdxscholar.library.pdx.edu/cengin_fac/419

This Post-Print is brought to you for free and open access. It has been accepted for inclusion in Civil and Environmental Engineering Faculty Publications and Presentations by an authorized administrator of PDXScholar. Please contact us if we can make this document more accessible: pdxscholar@pdx.edu. 


\title{
Lifecycle Modeling and Assessment of Unmanned Aerial Vehicles (Drones) CO2e Emissions
}

Miguel A. Figliozzi, PhD, Professor (corresponding author)

Department of Civil and Environmental Engineering

Portland State University

P.O. Box 751-CEE

Portland, OR 97207-0751

Phone: 503-725-4282

Fax: 503-725-5950

Email: figliozzi@pdx.edu

\begin{abstract}
There are no studies that model the potential effectiveness of Unmanned Aerial Vehicles (UAVs) or drones to reduce $\mathrm{CO}_{2} \mathrm{e}$ lifecycle (including both utilization and vehicle phase) emissions when compared to conventional diesel vans, electric trucks, electric vans, and tricycles. This study presents a novel analysis of lifecycle UAV and ground commercial vehicles $\mathrm{CO}_{2} \mathrm{e}$ emissions. Different route and customer configurations are modeled analytically. Utilizing real-word data, tradeoffs and comparative advantages of UAVs are discussed. Breakeven points for operational emissions are obtained and the results clearly indicate that UAVs are more $\mathrm{CO}_{2} \mathrm{e}$ efficient, for small payloads, than conventional diesel vans in a per-distance basis. Drastically different results are obtained when customers can be grouped in a delivery route. UAV deliveries are not more $\mathrm{CO}_{2} \mathrm{e}$ efficient than tricycle or electric van delivery services if a few customers can be grouped in a route. Vehicle phase $\mathrm{CO}_{2} \mathrm{e}$ emissions for UAVs are significant and must be taken into account. Ground vehicles are more efficient when comparing vehicles production and disposal emissions per delivery.
\end{abstract}

KEYWORDS: UAV drone; lifecycle emissions; energy efficiency; logistics last mile; electric vehicles; tricycles 


\section{Introduction}

Transportation accounts for a large share of total GHG emissions in most developed countries (Hertwich et al., 2009). Unmanned aerial vehicles (UAVs) have the potential to reduce costs and delivery times, but their potential impact on energy consumption and greenhouse gas (GHG) emissions is currently understudied. The real-world analysis conducted in this research is based on UAVs with electric engines because safety, noise, and pollution problems are likely to hinder the urban deployment of UAVs with internal combustion engines. However, the modeling approach can be applied to any type of UAV.

The focus of this research is on emissions tradeoffs between UAVs and different types of ground delivery vehicles. It has been correctly argued that the analysis of transportation systems energy and emissions levels should include not only direct tailpipe emissions but also emissions associated to vehicle production and disposal, the fuel/energy source, and required transportation infrastructure (Chester and Horvath, 2009). Lifecycle assessment (LCA) of vehicle emissions provides a more comprehensive view of transportation emissions that the traditional approach based on tailpipe emissions.

LCA separates emissions along life cycles or phases: extraction of raw materials from the earth, materials processing, manufacturing, distribution, product use and disposal or recycling at the end. We compare last-mile UAVs and ground vehicles lifecycle $\mathrm{CO}_{2} \mathrm{e}$ emissions in two distinct phases: (a) vehicle utilization and (b) vehicle production/disposal. In this research ground vehicle emissions associated to utilization includes well-to-tank (WTT) - the lifecycle of fuel production and distribution - and tank-to-wheel (TTW) or direct tailpipe emissions. These concepts are extended for the aerial vehicle or aircraft with an electric engine; for the UAV WTT emissions are replaced by generation-to-battery (GTB) and TTW emissions are replaced by battery-to-propeller (BTP) emissions. The vehicle phase (b) includes emissions from materials extraction and processing, manufacturing, distribution, and vehicle disposal or recycling but without considering vehicle utilization.

Unlike previous research efforts, this research compares UAV emissions not only against conventional diesel vehicles but also against more environmentally friendly electric trucks and electric tricycles. In addition, both operation and vehicle $\mathrm{CO}_{2} \mathrm{e}$ (carbon dioxide equivalent) emission phases are analyzed. The focus is on the derivation of breakeven points for the utilization phase as a function of the number of customer deliveries and other logistical parameters such as relative energy efficiency, service area size, and depot-service area distance. Vehicle phase emissions per delivery are also estimated and compared with emissions from the utilization phase.

\section{Literature Review}

Potential advantages and disadvantages of UAVs have been already considered by logistics companies. For example, the logistics services company DHL has identified higher last-mile efficiency, reduction of accidents, and faster deliveries as key potential UAV benefits; key potential challenges associated to UAVs are security, privacy, congestion, and regulatory concerns (Heutger and Kuckelhaus, 2014). Recently, UAVs have been featured frequently in the media following announcements made by large corporations such as Amazon (Anderson, 2004) but less frequently in the logistics academic literature.

The academic literature has already documented the advantages that UAVs can provide to deliver medicines in remote locations (Thiels et al., 2015). Other researchers have analyzed 
UAVs potential applications and challenges (Mohammed et al., 2014) and some authors have focused on the regulatory barriers that can preclude large UAV deployments (Boyle, 2015).

The academic literature discussing UAVs pros and cons or attempting to model UAV performance is rather scant. D'Andrea (2014) provided a succinct and preliminary discussion and modeling of UAV energy usage and delivery costs. Payload, lift-to-drag ratio, headwind, and travel speed do have a significant impact on UAV performance (D'Andrea, 2014).

Regarding UAV operational emissions, Goodchild and Toy (2017) compared VMT and $\mathrm{CO}_{2}$ emissions when deliveries are made by UAVs and conventional trucks. Real-world land use data and a GIS based approach was utilized to estimate customer locations and travel distances. The impact of different UAV energy consumption and emission levels were analyzed numerically. Truck emissions were a function of travel distance, vehicle year, and travel speed. Results suggest that UAVs emit less emissions when customers are located close to the depot and trucks emit less for faraway customers. The authors suggested that UAVs and trucks can complement each other. The idea of utilizing both UAV and trucks to improve overall delivery efficiency has also been analyzed by several authors but focusing on the actual design of routes and logistics systems (Mathew et al., 2015; Murray and Chu, 2015; Wang et al. 2017). Unlike this research, Toy and Goodchild (2016) do not estimate vehicle phase emissions or compare UAVs against cleaner ground vehicles such as tricycles or electric vehicles. In addition, this research provides detailed analytical formulas to estimate UAV emissions as a function of distance of payload or the number of stops (one-to-one and one-to-many service configurations).

Regarding UAV energy consumption, Choi and Schonfeld (2017) model the impact of battery capacity on payloads and flight ranges. Numerical analysis is utilized to optimize the drone fleet size and minimize delivery costs. This study concludes that UAV deliveries are more economical in areas with high customer density and that improved battery technology can significantly reduce UAV fleet size. There are tradeoffs associated to delivery speeds but clear benefits from longer hours of operation. Many papers in the applied electronics and engine control areas have focused on UAV technology, software, and design issues; these papers, for example Bristeau et al. (2011), are not reviewed herein because they are not directly relevant to the topic discussed in this paper.

Summarizing, there is a consensus in the literature that remote areas and dense urban areas are seen as promising environments for UAV deployment. Unlike previous research efforts, this research compares UAV emissions not only against conventional diesel vehicles but also against more environmentally friendly electric trucks and electric tricycles. Another contribution of this research is the analysis of vehicle production and disposal $\mathrm{CO}_{2} \mathrm{e}$ emissions and the derivation of formulas to estimate breakeven points for one-to-one and one-to-many route configurations. To the best of the author's knowledge, there are no scholarly articles that have analyzed and compared lifecycle $\mathrm{CO}_{2} \mathrm{e}$ emissions of UAVs and different ground vehicle types.

\section{Modeling UAV Steady Flight Energy Consumption}

Before estimating UAV emissions it is first necessary to estimate UAV energy consumption. There are many factors that affect airborne vehicles energy consumption. Drag, lift, weight, and thrust forces act over any self-propelled airborne vehicle such as airplanes, helicopters, and UAVs (Anderson and Eberhardt, 2001).

Maintaining a steady level flight requires a balance of forces, i.e. an equilibrium of all the forces acting upon an airborne vehicle. According to Newton's second law, any object moving in a steady level trajectory at a constant velocity has zero acceleration, all forces applied to the aircraft 
are balanced. For an airborne vehicle in a steady level trajectory there are four relevant forces: (i) weight, the force of gravity that acts in a downward direction, (ii) thrust, the force that propels the airborne vehicle in the direction of motion, (iii) lift, the force that acts at a right angle to the direction of motion through the air, and (iv) drag, the force that acts opposite to the direction of motion. When there is zero acceleration, level flight at a constant velocity, the lift balances the weight and the thrust balances the drag (Anderson and Eberhardt, 2001;D’Andrea, 2014).

$\mathrm{L}=\mathrm{W}, \mathrm{D}=\mathrm{T}$ and $\frac{\mathrm{L}}{\mathrm{D}} \mathrm{T}=m g$

where:

$\mathrm{D}=$ drag force $[\mathrm{N}]$

$\mathrm{T}=$ thrust force $[\mathrm{N}]$

$\mathrm{L}=$ lift force $[\mathrm{N}]$

$\mathrm{W}=$ weight force $[\mathrm{N}]$

$m=$ mass $[\mathrm{kg}]$

$g=$ gravity acceleration $\left[\mathrm{m} / \mathrm{s}^{2}\right]$.

An electric cargo UAV has three key mass components: vehicle, battery, and load. For aircrafts, the lift-to-drag ratio or L/D ratio is a key characteristic affecting flight efficiency and the power necessary to fly as a function of travel speed. By disaggregating the vehicle weight into its components and then multiplying by travel speed, it is possible to obtain the theoretical power necessary to move the aircraft :

$p_{t}=\mathrm{T} s=\left(m_{t}+m_{b}+m_{l}\right) g \frac{s}{\vartheta(s)}$

where:

$p_{t}=$ theoretical power required for level flight [watts]

$S=$ constant velocity travel speed $[\mathrm{m} / \mathrm{s}]$

$\vartheta(s)=$ lift-to-drag ratio or L/D [unit-less]

$m_{t}=\mathrm{UAV}$ mass tare, i.e. without battery and load $[\mathrm{kg}]$

$m_{b}=\mathrm{UAV}$ battery mass $[\mathrm{kg}]$

$m_{l}=\mathrm{UAV}$ load mass $[\mathrm{kg}]$

$m=$ UAV total mass when loaded [kg], $m=m_{t}+m_{b}+m_{l}$.

The energy necessary to travel a given distance is equal to power by travel time and also affected by the power transfer efficiency from the battery to the propellers (energy loss). The power required for level flight is:

$p_{l} t=\frac{\left(m_{t}+m_{b}+m_{l}\right) g}{\vartheta(s) \eta_{p}} d$

where:

$p_{l}=$ power required for level flight [watts]

$t=$ travel time $[$ seconds $]=d / s$

$d=$ travel distance $[\mathrm{m}]$ 
$\eta_{p}=$ total power transfer efficiency [unit-less] $<1$.

From (1) it is possible to observe that energy consumption is directly proportional to aircraft mass and travel distance. Expression (1) does not include the power needed to feed the sensors and other electronics that is relatively small for a long-range delivery drone. Travel speed drops out of expression (1), however, the ratio between Lift and Drag is typically a function of travel speed. For each aircraft there is a speed where L/D is highest or optimal which is defined as $\vartheta^{*}$. Cargo airplanes are more energy efficient than helicopters and UAVs; airplanes $\vartheta^{*}$ values, in the range of 10 to 20 , are several times higher than helicopters $\vartheta^{*}$ values, in the range of 3.5 to 5.0 (Leishman, 2006).

\section{Modeling One-to-one Energy Consumption}

In this scenario, a vehicle (UAV or van) travels to a destination and drops its load and then returns empty. By reversing the order, it is possible to model a pick-up. Without loss of generality dropoff services will be assumed herein. Due to noise and pollution concerns, it will be also assumed that electric UAVs are utilized for urban services (internal combustion engines pollute more and are noisier). Only one vehicle is utilized, i.e. there is no load transfer or intermediate depots. Utilizing expression (1) the energy consumed by a UAV to reach a customer and travel back empty is:

$\frac{\left(m_{t}+m_{b}+m_{l}\right) g}{\vartheta(s) \eta_{p}} d+\frac{\left(m_{t}+m_{b}\right) g}{\vartheta(s) \eta_{p}} d$

This expression can be simplified utilizing $c_{m}$ the ratio between the tare and the gross vehicle weight of the UAV, i.e. the ratio between the weight of the unloaded UAV and the weight of the fully loaded UAV. In the case of electrical batteries, the weight of the battery does not change as a function of distance traveled. However, when batteries are charged there are losses that are captured by the recharging efficiency. The total energy consumed to serve one customer is:

$E_{1}^{u}=\frac{g d}{\vartheta(s) \eta_{p} \eta_{r}}\left(m_{t}+m_{b}+m_{l}\right)+\left(m_{t}+m_{b}\right)=\frac{g d m}{\vartheta(s) \eta_{p} \eta_{r}}\left(1+c_{m}\right)$

where:

$E_{1}^{u}=\mathrm{UAV}$ energy necessary to serve one customer [joules]

$c_{m}=$ empty weight fraction [unit-less], $c_{m}=\frac{\left(m_{t}+m_{b}\right)}{\left(m_{t}+m_{b}+m_{l}\right)}<1$

$\eta_{r}=$ battery recharging efficiency [unit-less]

The energy necessary to serve one customer utilizing a conventional vehicle can be expressed as:

$E_{1}^{c}=2 k_{c} d f_{e} c_{f}$

where:

$E_{1}^{c}=$ conventional vehicle energy necessary to serve one customer [joules]

$f_{c}=$ fuel consumption [liters $\left./ 100 \mathrm{~km}\right]$

$c_{f}=$ conversion fuel energy factor $[\mathrm{J} /$ liter $]$

$k_{c}=$ depot-customer distance circuitous factor relative to the UAV[unit-less] 
In this research, it is assumed that $k_{c}=1.0$ unless stated otherwise. The energy needed per unit distance traveled can be obtained by dividing expressions (2) and (3) by $2 d$. The result is respectively:

$e_{1}^{u}=\frac{g m}{\vartheta(s) \eta_{p} \eta_{r}} \frac{1+c_{m}}{2}=$

$e_{1}^{c}=k_{c} f_{e} c_{f}$

where:

$e_{1}^{u}=\mathrm{UAV}$ energy necessary to serve one customer per unit of distance traveled [joules/meter]

$e_{1}^{c}=$ Commercial vehicle energy necessary to serve one customer per unit of distance traveled [joules/meter]

To quantify the energy efficiency of UAVs, the ratio of expressions (5) and (4) can be estimated as follows:

$\rho_{1}^{e n}=\frac{2 k_{c} c_{f} f_{c} \vartheta(s) \eta_{p} \eta_{r}}{g m\left(1+c_{m}\right)}$

where:

$\rho_{1}^{e n}=$ relative energy efficiency of UAVs when serving one (1) customer (one-to-one service)

It can be observed from (6) that distance to the customer drops out from the expression. As expected, the relative efficiency of UAVs increases as the mass of the UAV decreases, when the cargo has a higher share of the total UAV mass, and when the UAV power delivery and battery recharging efficiencies increase. The relative efficiency of the UAV decreases when the fuel consumption of the conventional vehicle decreases.

\section{Modeling $\mathrm{CO}_{2} \mathrm{e}$ utilization emissions}

For conventional vehicles, the carbon footprint of the vehicle utilization phase includes Well-toTank (WTT) - emissions that take place along the fuel/energy supply chain - and Tank-to-wheel (TTW) - emissions associated to the combustion of the fuel. For a UAV, the carbon footprint includes Generation-to-Battery (GTB) emissions associated to the electricity supply chain and Battery-to-Propeller (BTP) emissions. For electric UAVs, the BTP component is zero.

WTT emissions for fossil fuels include several stages: petroleum pumping, extracting, transporting, refining in factories, distributing, and dispensing to the vehicles. WTT emissions are estimated using the GREET model (USDoE, 2016); $5.1 \mathrm{lbs}$ CO2e/gallon of diesel or $0.22 \mathrm{~kg}$ $\mathrm{CO} 2 \mathrm{e} / \mathrm{liter}$ of diesel. The TTW emissions associated to burning one gallon of diesel is approximately $22.7 \mathrm{lbs}$ CO2e/gallon of diesel or $2.7 \mathrm{~kg} \mathrm{CO} 2 \mathrm{e} / \mathrm{liter}$ of diesel (USEPA, 2017). The Emissions \& Generation Resource Integrated Database (eGRID), published by the U.S. Environmental Protection Agency, is utilized to estimate GTB emissions (USEPA, 2016). The eGRID values include the generation of electricity at the power plants as well as electricity transmission and distribution losses. The operational GHG emissions per mile are calculated for each vehicle using the following expressions for UAVs and diesel vehicles respectively. 


$$
\begin{aligned}
& \mathrm{Co}_{2} e^{u} \frac{E_{n}^{u} f e_{g t b}}{2 r n}=\frac{g m}{\eta_{p} \eta_{m} \eta_{a} \vartheta(s)} \frac{\left(1+c_{m}\right)}{2} f_{k w h} e_{g t b} \\
& \mathrm{Co}_{2} e^{c}=100 f_{c}\left(e_{w t t}+e_{t t w}\right)
\end{aligned}
$$

where:

$\mathrm{CO}_{2} e^{u}=\mathrm{UAV}$ equivalent carbon dioxide emissions per unit of distance traveled [kg.CO2e $/ \mathrm{km}]$

$\mathrm{CO}_{2} e^{c}=$ van equivalent carbon dioxide emissions per unit of distance traveled [kg.CO2e $/ \mathrm{km}$ ]

$f_{k w h}=$ factor to convert Joules to $\mathrm{kWh}=1 / 3.610^{6}$ [ $\mathrm{kWh} /$ Joule]

$e_{g t b}^{i}=$ emissions of the GTB phase [ kg.CO2e / kWh)]

$e_{w t t}^{i}=$ emissions of the WTT phase [kg.CO2e / liter)]

$e_{t t w}^{i}=$ emissions of the TTW phase [ kg.CO2e / liter)]

The ratio of expressions (8) and (7) is $\rho_{1}^{e m}$ or the relative emissions efficiency per unit distance of UAVs with respect to ground vehicles. If expressions (7) and (8) are divided by payload, it is possible to estimate the efficiency per unit of distance and payload.

\section{Results for One-to-one Routes}

This section applies the formulas developed in the previous sections to compare the energy and emissions efficiency of a typical USA conventional cargo van and a mainstream UAV assuming one-to-one deliveries (one customer per route). Table 1 shows the relevant aircraft and vehicle characteristics. Data for the cargo van was obtained from Saenz et al. (2016) and data for the MD4-3000 UAV was obtained from the manufacturer's website (MicroDrones, 2017).

TABLE 1. Vehicle characteristics and emissions parameters**

\begin{tabular}{lll}
\hline & UAV & Diesel cargo van \\
\cline { 2 - 3 } Specification & MD4-3000 & RAM ProMaster 2500 \\
\hline Take off / Gross weight $m$ & $15.1 \mathrm{~kg}$ & $4060 \mathrm{~kg}$ \\
Tare / Curb Weight $m_{t}$ & $10.1 \mathrm{~kg}$ & $2170 \mathrm{~kg}$ \\
Payload $m_{l}$ & $5.0 \mathrm{~kg}$ & $1890 \mathrm{~kg}$ \\
Empty weight factor $c_{m}$ & 0.67 & 0.53 \\
Battery/Fuel Storage Capacity* & $777 \mathrm{wh}$ & $8.63 \mathrm{kWh}$ \\
$e_{g t b}$ or $e_{w t t}$ & $1.235 \mathrm{lbs}$ CO2e / kWh & $5.108 \mathrm{lbs}$ CO2e / gallon \\
$e_{b t p}$ or $e_{t t w}$ & - & $22.72 \mathrm{lbs}$ CO2e / gallon \\
Range & $36 \mathrm{~km}$ & $695 \mathrm{~km}$ \\
Energy/fuel consumption & $21.6 \mathrm{wh} / \mathrm{km}^{*}$ & $1016 \mathrm{wh} / \mathrm{km}^{*}$ \\
\hline
\end{tabular}

* calculated utilizing manufacturer information and it was assumed that the energy content of gasoil is $34200 \mathrm{~kJ} / \mathrm{liter}$ and therefore $22 \mathrm{mpg}=1016 \mathrm{wh} / \mathrm{km} * *$ To improve readability numbers have been rounded. 
The MD4-3000 is a state of the art UAV that can be used to carry objects or for aerial photography/filming purposes. The manufacture website contains all the data that are necessary to estimate energy consumption for a given load. The MD4-3000 capabilities seem similar to the HorseFly UAV tested by UPS in Feb. 2017. The battery-powered HorseFly drone recharges while docked in the UPS van has a 30-minute flight time and can carry a package weighing up to $4.5 \mathrm{~kg}$ (HorseFly, 2017). A more detailed discussion of state of the art UAV multicopters and their logistical capabilities is found in Figliozzi and Tucker (2017).

When comparing the aircraft and the vehicle, there is a large difference in vehicle mass, carrying capacity, engine power, and energy stored. The application of the formulas developed in the previous sections generate the numbers contained in Table 2 . Assuming a payload of $5.0 \mathrm{~kg}$, the UAV is almost 47 times more efficient $\left(\rho_{1}^{e n}=47\right)$ than the van in terms of energy consumed per unit distance. The same energy is consumed if the van travels one time and delivers 47 packages at once (assuming UAV utilizes $21.6 \mathrm{wh} / \mathrm{km}$ ) or if the UAV travels back and forth 47 times and delivers one package at the time.

What is generating this $\rho_{1}^{e n}=47$ value? It is possible to disaggregate $\rho_{1}^{e n}$, i.e. expression (6), into two components assuming that $k_{c}=1$ :

$$
\begin{array}{ll}
1<\frac{2}{\left(1+c_{m}\right)}<2 & \text { [unit-less] } \\
\frac{c_{f} f_{c}}{g m /\left(\vartheta(s) \eta_{p} \eta_{r}\right)} & \text { [unit-less] }
\end{array}
$$

The first term is bounded in the interval $(1,2)$ and is a function of the relative mass size of the load with respect to the total UAV mass and approximately equal to 1.2 in the case study. The second term is approximately 39 and accounts for the large difference in energy consumption between the conventional vehicle and the UAV. This term can be interpreted as the ratio between the energy necessary to move (per unit distance) the van and the energy necessary to move (per unit distance) a mass equivalent to the UAV mass.

There is a significant mass difference between the van and the UAV. But also electric engines produce simpler and more efficient machines. The product $\eta_{p} \eta_{r}$ is the overall efficiency to deliver power to the battery and then to the propellers and is assumed to be $(0.90)(0.73)=0.66$; in comparison, typical diesel vehicles may utilize $25 \%$ of the potential energy stored in the fuel to move the vehicle (most of the energy contained in diesel fuel is dissipated as heat).

If the analysis is done in terms of emissions per unit distance, the advantage of the UAV is even higher because electricity generation is "greener" per unit of energy than diesel fuel. The electricity consumed for the UAV is more than 22 times cleaner than the energy consumed by the van and the ratio between van and $\mathrm{UAV} \mathrm{CO} 2 \mathrm{e}$ emissions per unit distance is $\rho_{1,1}^{e m}=1,056$.

TABLE 2. One-to-one service performance measures*

\begin{tabular}{lcccc}
\hline \multicolumn{1}{c}{ Performance Measure } & Unit & $\begin{array}{c}\text { Van } \\
(\mathbf{1})\end{array}$ & $\begin{array}{c}\text { UAV } \\
(\mathbf{2})\end{array}$ & $\begin{array}{c}\text { Ratio } \\
(\mathbf{1}) /(\mathbf{2})\end{array}$ \\
\hline Energy consumed per unit distance & $\mathrm{wh} / \mathrm{km}$ & 1,016 & 21.6 & 47 \\
Emissions per unit energy consumed & $\mathrm{gCo} 2 \mathrm{e} / \mathrm{wh}$ & 12.6 & 0.6 & 22.5
\end{tabular}




\begin{tabular}{lcccc} 
Emissions per unit distance & $\mathrm{kgCO} 2 \mathrm{e} / \mathrm{km}$ & 12.83 & 0.012 & 1,056 \\
Payload & $\mathrm{kg}$ & 1,890 & 5.0 & 378 \\
Energy cons. per unit distance-load & $\mathrm{wh} / \mathrm{km}-\mathrm{kg}$ & 0.54 & 4.32 & 0.12 \\
Emissions per unit distance-load & $\mathrm{kgCO} e \mathrm{e} / \mathrm{km}-\mathrm{kg}$ & 6.79 & 2.42 & 2.8 \\
\hline
\end{tabular}

* To improve readability numbers have been rounded.

The performance measures are more favorable for the conventional van when the analysis is done in terms of energy consumption and emissions per unit distance and per kilogram of payload delivered. The van can deliver 378 times more cargo than the UAV; assuming maximum payloads the van is 8 times $(1 / 0.12)$ more efficient in terms of energy consumption but still almost 2.8 times less efficient regarding GHG emissions.

\section{Modeling One-to-many Routes}

This section presents the analytical framework to analyze the efficiency of ground vehicles when several costumers can be grouped in a route (one-to-many configuration). In this scenario, there are two or more customers per route that are served by the same ground vehicle (one ground vehicle and many stops or customers per route).

The ground delivery vehicle can combine customers in one route; however, the UAV cannot do multiple drops without first returning to the depot to reload. The UAV travels to a destination, drops its load and then returns empty to the launching location where a new package is loaded, and so on (still one-to-one service for UAVs). For the sake of simplicity, it is assumed that there are $n$ customers that are delivered the type of same package (weight).

Assuming that a UAV can serve only one customer at the time due to volume and/or weight limitations, the energy necessary to serve $n$ customers by a UAV is:

$E_{n}^{u}=\frac{n g r m}{\eta_{p} \eta_{a} \vartheta(s)}\left(1+c_{m}\right)$

where:

$E_{n}^{u}=\mathrm{UAV}$ energy necessary to serve $n$ customers [joules]

Conventional vehicles typical delivery (or pick-up) routes serve many customers. Continuous approximation models can be utilized to model the average distance traveled to serve $n$ customers (Daganzo, 2005). A continuous approximation formula, empirically validated, that is appropriate for customer delivery areas that are located away from the depot is the following (Figliozzi, 2008):

$d_{n}=2 k_{c} \bar{d}+k_{l} \sqrt{n A}$

where:

$d_{n}=$ average distance traveled to serve $n$ customers by one vehicle $[\mathrm{km}]$,

$\bar{d}=$ average distance between customers and the depot $[\mathrm{km}]$,

$n=$ number of stops or deliveries [unit-less],

$A=$ size of service area containing $n$ customers $\left[\mathrm{km}^{2}\right]$

$k_{l}=$ local customer distribution distance circuitous factor [unit-less]. 
Then, the energy necessary to serve $n$ customers utilizing $v$ conventional vehicles is:

$E_{n}^{c}=c_{f} f_{c}\left[2 k_{c} \bar{d}+k_{l} \sqrt{n A}\right]$

The the ratio of expressions $E_{n}^{c}$ and $E_{n}^{u}$ can be estimated as follows:

$\rho_{n}^{e n}=\frac{c_{f} f_{c}\left[2 k_{c} \bar{d}+k_{l} \sqrt{n A}\right] \vartheta(s) \eta_{p} \eta_{r}}{n \bar{d} \operatorname{gm}\left(1+c_{m}\right)}$

where $\rho_{n}^{e n}$ is the relative energy efficiency of UAVs when one ground vehicle serves $n$ customers per route (one-to-many service). As done previously, it is possible to disaggregate expression (9) into the following unit-less components:

$\begin{array}{ll}0<\frac{1}{\left(1+c_{m}\right)}<1 & \text { [unit-less] } \\ 0<\eta_{p} \eta_{r}<1 & \text { [unit-less] } \\ \frac{c_{f} f_{c}}{g m / \vartheta(s)} & \text { [unit-less] } \\ \frac{2 k_{c} \bar{d}+k_{l} \sqrt{n A}}{n \bar{d}} & \text { [unit-less] }\end{array}$

Distance traveled increases linearly with the number of customers for the UAV but at lower rate for the conventional vehicle. This is reflected in expression (10) that is the ratio between conventional vehicle distance and UAV distance; as $n$ increases the relative efficiency of the UAV decreases continuously. Hence, there is a breakeven point for a large enough $n$.

\section{Results for One-to-many Routes}

This section utilizes the same vehicle and UAV already described in the one-to-one case study. Average travel distances and distribution areas that are approximately binding the UAV $25 \mathrm{~km}$ range constraint are utilized in this section; the reader should not that this is the most favorable scenario for UAVs. A $25 \mathrm{~km}$ distance is approximately $70 \%$ of the maximum UAV theoretical range, in practice the UAV operator has to provide a margin of safety and account for unknown factors that can increase energy consumption such as headwinds.

When assuming a constant and binding UAV range, average distances between depot to customers and service areas are negatively correlated (see Table 3 ). In Table 3 the value $n^{*}$ is the breakeven point or the number of customers that equalizes the efficiency of a UAV and a conventional vehicle. There are three columns under $n^{*}$, the central column under $21.6 \mathrm{wh} / \mathrm{km}$ contains the breakeven point based on the efficiency estimated from the UAV manufacturer specifications. The left column under $10.8 \mathrm{wh} / \mathrm{km}$ contains breakeven points based on the efficiency of a future UAV whose efficiency has doubled. The right column under $32.4 \mathrm{wh} / \mathrm{km}$ contains breakeven points for a MD4-3000 UAV whose efficiency has decreased by 50\%. This low efficiency is not unrealistic under adverse conditions that included more headwinds, 
hovering time, or maneuvering up/down/sideways to avoid obstacles, reach destination, or complete the delivery.

TABLE 3. UAV and Diesel Van Breakeven Energy Scenarios - One-to-one Routes

\begin{tabular}{|c|c|c|c|c|}
\hline $\begin{array}{l}\text { Avg. Dist. depot } \\
\text { to } \\
\text { Customers (km) }\end{array}$ & $\begin{array}{c}\text { Service } \\
\text { Area }\left(\mathrm{km}^{2}\right)\end{array}$ & $\begin{array}{l}\rho_{1}^{e n} \sim 94 \\
10.8 \\
\mathrm{wh} / \mathrm{km}\end{array}$ & $\begin{array}{c}\boldsymbol{n}^{*} \\
\rho_{1}^{e n} \sim 47 \\
21.6 \\
\text { wh/km } \\
\end{array}$ & $\begin{array}{c}\rho_{1}^{e n} \sim 31 \\
32.4 \\
\text { wh/km } \\
\end{array}$ \\
\hline 8 & 60 & 1,340 & 362 & 173 \\
\hline 9 & 40 & 785 & 224 & 113 \\
\hline 10 & 20 & 413 & 131 & 72 \\
\hline 11 & 7 & 219 & 83 & 50 \\
\hline 12 & 1 & 127 & 58 & 37 \\
\hline
\end{tabular}

The figures in Table 3 show that there is a positive correlation between service area size and breakeven number of customers and a negative correlation between depot distance and breakeven number of customers. As a reference, a typical UPS delivery truck in a dense urban area can deliver 200 to 300 pieces and packages. In some cases, where there are multiple deliveries of pieces/packages at the same address - e.g. a large office complex, the number can go up to 300 to 500 pieces. Under adverse delivery conditions, that UAV is not competitive if the truck can deliver more than 50 packages in a dense area.

In terms of emissions, given that $\rho_{1}^{e m}=1056$ is so high, in practice it difficult to find delivery routes where the van is more efficient than an electric UAV in terms of operational emissions. The same emissions are generated if the van travels one time and delivers 1056 packages at once or if the UAV travels back and forth 1056 times and delivers one package at the time.

An electric truck will be more competitive in terms of energy and emissions. When comparing an electric truck and UAV the relative efficiencies in terms of energy and emissions are the same, i.e. $\rho_{1}^{e n}=\rho_{1}^{e m}$, because the same energy source is utilized to power the electric engines. Assuming that the electric truck has an energy consumption of $760 \mathrm{wh} / \mathrm{km}$ (Davis and Figliozzi 2013; Feng and Figliozzi, 2013), then $\rho_{1}^{e n}=\rho_{1}^{e m}=35$. Table 4 shows the results assuming that one electric truck serves the one-to-many route. There is a noticeable decrease in the values of $n^{*}$ and electric trucks can now compete with UAVs in terms of both energy and emissions efficiency in realistic routes with more than 50 customers and/or a relatively small delivery area.

Electric vehicles have steadily become more efficient in the last five years. There are also now in the market (in Europe mainly) small electric vans. For example, the 2017 Renault ZE Kangoo has a payload of $600 \mathrm{~kg}$ and will consume approximately $205 \mathrm{wh} / \mathrm{km}$ in temperate temperatures (Renault, 2017). The $205 \mathrm{wh} / \mathrm{km}$ value used in table 4 is more conservative than the ideal value given by the manufacturer $(150 \mathrm{wh} / \mathrm{km})$. Against an electric van that can carry 120 times more cargo, the UAV is not competitive in dense delivery areas with more than 10 customers per route as shown in Table 4 - right column. 
TABLE 4. UAV and Electric Van Breakeven Scenarios - One-to-one Routes

\begin{tabular}{cccc}
\hline $\begin{array}{c}\text { Avg. Dist. depot } \\
\text { to }\end{array}$ & $\begin{array}{c}\text { Service } \\
\text { Area }\left(\mathrm{km}^{2}\right)\end{array}$ & $\begin{array}{c}\boldsymbol{n}^{*} \\
\boldsymbol{\rho}_{\mathbf{1}}^{\boldsymbol{e n}} \sim \mathbf{3 5} \\
\text { vs. E-truck }\end{array}$ & $\begin{array}{c}\boldsymbol{n}^{*} \\
\boldsymbol{\rho}_{\mathbf{1}}^{\boldsymbol{e n}} \sim \mathbf{9 . 5} \\
\text { vs. E-van }\end{array}$ \\
\hline 8 & 60 & 214 & 26 \\
9 & 40 & 137 & 20 \\
10 & 20 & 85 & 15 \\
11 & 7 & 58 & 12 \\
12 & 1 & 42 & 10 \\
\hline
\end{tabular}

An electric tricycle is even more efficient than an electric truck or van in terms of energy consumption and emissions. According Saenz et al. (2016) the real-world energy consumption of a delivery tricycle is approximately $48.65 \mathrm{wh} / \mathrm{mile}$ or $30.24 \mathrm{wh} / \mathrm{km}$. With this value, the relative efficiency between an UAV and an electric tricycle is $\rho_{1}^{e n}=\rho_{1}^{e m}=1.4$. When then number of customers per route is relatively small $(n<10)$ the following expression (Figliozzi, 2008) is a better approximation for the VRP distance (used for the tricycle case):

$d_{n}=2 k_{c} \bar{d}+k_{l}\left(\frac{n-m}{n}\right) \sqrt{n A}$

Table 5 shows the results assuming that one electric tricycle serves the one-to-many route. There is a sharp decrease in the values of customers needed to breakeven; tricycles outcompete UAVs in terms of efficiency when two or more customers can be grouped in a route. In Table 5 the values of $n^{*}$ are so small that decimals are necessary to show changes. Against an electric tricycle that can carry 40 times more cargo, the UAV is not competitive in routes where it is possible to group two or more customers.

TABLE 5. UAV and Electric Tricycle Breakeven Scenarios - One-to-one Routes

\begin{tabular}{ccr}
\hline $\begin{array}{c}\text { Avg. Dist. depot } \\
\text { to } \\
\text { Customers (km) }\end{array}$ & $\begin{array}{c}\text { Service } \\
\text { Area }\left(\mathrm{km}^{2}\right)\end{array}$ & $\begin{array}{c}\boldsymbol{n}^{*} \\
\boldsymbol{\rho}_{\mathbf{1}}^{\text {en }} \sim \mathbf{1 . 4} \\
\text { vs. E-tricycle }\end{array}$ \\
\hline 8 & 60 & 2.1 \\
9 & 40 & 1.9 \\
10 & 20 & 1.7 \\
11 & 7 & 1.6 \\
12 & 1 & 1.5 \\
\hline
\end{tabular}

The competitiveness of ground vehicles is even higher if vehicle phase emissions are also taken into account as discussed in the next section. 


\section{Vehicle Phase: $\mathrm{CO}_{2}$ e Production and Disposal}

In the previous sections a detailed analysis of operating emissions was presented, including both WTT and TTW $\mathrm{CO}_{2} \mathrm{e}$ emissions for ground vehicles and GTB and BTP $\mathrm{CO}_{2} \mathrm{e}$ emissions for UAVs. This section focuses solely on the vehicle production and disposal phase. The vehicle phase includes emissions associated to the extraction of raw materials from the earth, raw materials processing, manufacturing, distribution, and disposal or recycling at the end.

GHG emissions for the vehicle phase are estimated using the GREET model which uses vehicle weight as the functional unit (USDOE, 2016). The GREET model contains hundreds of parameters with default values based on national/regional statics or industrial practice. Detailed documentation of assumptions in relation to industrial processes and technologies are available on GREET publications (USDOE, 2016). For diesel vans and electric tricycles, the same values utilized in previous research efforts are employed. Regarding UAVs, the GREET model does not include a UAV vehicle type. Unlike other flying machines, a major component of the UAV weight is the lithium-ion polymer battery. Hence, the electric UAV was modeled as the sum of two elements: (a) the lithium-ion batteries and (b) the rest of the UAV (engines, sensors/processors, and the body/frame). Battery lifecycle values were obtained from the paper by Kim et al. (2016) that analyzed electric vehicles lithium-ion batteries.

The results of the analysis are shown in Table 6. The UAV has a much smaller mass and lower vehicle phase emissions per vehicle but the battery is $40 \%$ of its tare. Due to the long recharge time, it is common to have three or more batteries per UAV. Conservatively, only four batteries over the lifetime of the drone are assumed; this is a conservative estimate because a properly maintained lithium-ion polymer battery have less than 1000 recharge cycles on average (Peters et al., 2017). In addition, in proportion to its weight the UAV has more processors, sensors, electronics, and other aircraft materials that are more energy intensive to produce and recycle; hence the UAV has a significantly higher rate of $\mathrm{CO}_{2} \mathrm{e}$ emissions per vehicle mass and per payload mass - see rows three and four of Table 6 .

TABLE 6. Vehicle Phase CO2e Emissions (**)

\begin{tabular}{lrrr}
\hline Parameter & UAV & Tricycle & Diesel Van \\
\hline Batteries (kg CO2e) & 435 & 306 & $\left(^{*}\right)$ \\
Vehicle (kg CO2e) & 56 & 346 & 10,076 \\
Emissions per unit of vehicle mass & & & \\
or tare (kg CO2e per kg) & 48.6 & 8.7 & 4.6 \\
Emissions per unit of payload mass & & & \\
$(\mathrm{kg} \mathrm{CO} e$ per kg) & 69.2 & 2.6 & 5.3
\end{tabular}

(*) Included in the vehicle chassis (**) To improve readability numbers have been rounded

To estimate the UAV vehicle phase emissions the following formula was utilized:

$n_{b} w_{b} e_{b}+m_{t} e_{t}$ 
where:

$n_{b}$ : number of batteries utilized during the UAV lifetime

$e_{b}$ : emissions per kwh (140 kg CO2e per kwh battery)

$w_{b}$ : battery storage capacity $(777 \mathrm{wh})$

$e_{t}$ : emissions per vehicle tare weight $(9.3 \mathrm{~kg} \mathrm{CO} 2 \mathrm{e}$ per $\mathrm{kg})$

To compare vehicle phase emissions with utilization emissions it is necessary to estimate vehicle phase emissions per delivery assuming values for the average number of deliveries per day, number of vehicle working days per year, and vehicle productive life. It was already mentioned that in an urban area, a parcel delivery van can easily deliver 150 or more parcels per day; the van assumed in this research can carry up to 375 packages if each package weighs $5 \mathrm{~kg}$. A tricycle is more limited in terms of operating speed and capacity and the number of deliveries per day is around 25 stops or customers per day (Saenz et al. 2016) but it can carry up to 54 packages if each package weighs $5 \mathrm{~kg}$. It is assumed that on average four deliveries per day are made by the UAV. Three years may be considered an optimistic guess given that UAV-multicopters is a very young technology. Unfortunately there is no available data regarding UAV life and average deliveries per day but these numbers can be easily updated when data become available. The total number of deliveries over the lifetime of a vehicle is simply the product of working life duration (years) by service days per year (days/year) and by average deliveries per day (deliveries/day).

Table 7 shows the $\mathrm{CO}_{2} \mathrm{e}$ efficiency per delivery with the assumed values. Different assumptions will lead to different values but on a per delivery basis the tricycle and diesel van seem to have a clear advantage (fourth row of Table 7). To compare the results it is useful to obtain the equivalent travel distance that will produce the same level of vehicle phase emissions per delivery (fifth row of Table 7). Vehicle phase emissions per delivery are a negligible addition for the diesel van but a major addition for the UAV. The UAV vehicle phase emissions per delivery are of the same order of magnitude as half the practical range of the UAV. Hence, the UAV emissions per delivery can increase by up to $50 \%$ when the vehicle phase is taken into account. Taking into account both operational and vehicle phases the tricycle is likely to be more $\mathrm{CO}_{2} \mathrm{e}$ efficient than the UAV. 
TABLE 7. Per Delivery Vehicle Phase $\mathrm{CO}_{2} \mathrm{e}$ Emissions (**)

\begin{tabular}{lrrr}
\hline Parameter & UAV & Tricycle & Diesel Van \\
\hline Number of daily deliveries & 4 & 25 & 150 \\
Delivery days per year (days) & 260 & 260 & 260 \\
Vehicle life (years) & 3 & 5 & 10 \\
Emissions per delivery & & & \\
(kg CO2e per delivery) & 0.16 & 0.02 & 0.03 \\
Equivalent travel distance (in km) & & & \\
(kg CO2e per delivery) & 13.0 & 1.2 & 0.002 \\
Range (km) & 25 & 48 & 625 \\
Equivalent travel distance as \% of range & 52 & 2.5 & 0.0 \\
\hline
\end{tabular}

(*) Included in the vehicle chassis (**) To improve readability numbers have been rounded

\section{Conclusions}

This research has introduced a novel framework to analyze the real-world energy and emissions efficiency of UAVs and different ground commercial vehicles. The results of the analysis show that UAVs can significantly reduce operational first/last mile energy consumption and emissions (both well-to-tank and tank-to-wheel) in some scenarios. The analysis utilizing real-world data indicates that UAVs, presently available in the market, are significantly more $\mathrm{CO}_{2} \mathrm{e}$ efficient (around 47 times) than typical US diesel delivery vehicles in terms of energy consumption. In terms of emissions the differences are even greater (more than 1000 times). However, the efficiency measures are more favorable for the conventional van when the analysis is done in terms of energy consumption and emissions per unit distance and per kilogram of payload delivered. The van can deliver almost 380 times more cargo than the UAV; assuming maximum payloads the typical US van is 8 times more efficient in terms of energy consumption but still almost 2.8 times less efficient regarding GHG emissions. Electric trucks and vans are much more efficient than the typical US van. Hence, the UAV is not more efficient than electric vans in delivery scenarios with more than 10 customers per route.

The lifecycle analysis shows that UAV vehicle phase emissions are significant and must be taken into account. When vehicle phase emissions are considered, the UAV lifecycle efficiency can be reduced by a significant amount. Considering lifecycle emissions, an electric tricycle is likely to be more $\mathrm{CO}_{2}$ e efficient than the UAV. Hence, in dense urban areas where tricycle deliveries are economically feasible (Tipagornwong and Figliozzi, 2014) tricycles are likely to outperform UAVs in terms of both energy consumption and lifecycle $\mathrm{CO}_{2}$ e emissions. A factor that may significantly favor UAVs is a shorter travel distance as the crow flies than on the ground - a shorter distance would result in a smaller circuitousness factor or $k_{c}$ for the UAV and less emissions. However, at this time there is no reliable research or value to quantify the difference between $k_{c}$ factors for UAVs and ground vehicles in urban and/or rural areas. 
Although it is expected that small UAV technology, capabilities, and costs will improve substantially in the near future (Floreano and Wood, 2015), it is implausible that UAVs will outcompete commercial vehicles in some scenarios. Conventional vehicles outperform UAVs in cases where payloads are not small or if a customer is located far beyond the relatively limited range of a UAV - range is a function of payload and other variables but for small quadcopter UAVs practical range is currently less than 25 kilometers. Breakthroughs in UAV technologies may affect the typical range of UAVs energy consumption (assumed to be 10 to $32 \mathrm{wh} / \mathrm{km}$ in this research). For example, small fixed wing UAVs with VTOL (vertical take-off and landing) capabilities may become suitable one day for urban deliveries. Fixed wing UAVs are considerable more energy efficient than multicopters in terms of energy consumption per unit distance flown. The methodology develop in this research will still be applicable even if there are major improvements in terms of UAV design, battery energy storage, range, and carrying capacity.

Currently, in sparsely populated areas with a low number of customers and density, UAVs can fill a service niche while substantially lowering energy and emissions per service when the payloads are relatively small. UAVs can also reduce significantly energy consumption and emissions in urban areas with high congestion and low commercial vehicle fuel/energy efficiency. However, in dense urban areas, several first/last mile service, privacy, regulatory and security issues must be first addressed before UAV services are feasible. In addition, in urban areas, clean ground vehicles like tricycles may be more lifecycle $\mathrm{CO}_{2} \mathrm{e}$ efficient than UAVs if several customers can be grouped in a route.

\section{Acknowledgements}

This research was funded by the Freight Mobility Research Institute (FMRI) USDOT University Transportation Center. Any errors or omissions are the sole responsibility of the author.

\section{References}

Anderson, M. Amazon Seeks FAA Approval to Test Delivery Drones Outdoors, The Seattle Times. 11 July 2014. Web accessed on 25 Nov. 2014 and Amazon Prime Air UAV logistics program https://www.amazon.com/b?node=8037720011

Anderson, D., Eberhardt, S. Understanding Flight (2001), McGraw-Hill, 2001, ISBN: 0-07136377-7

Boyle, M. J. (2015). The race for drones. Orbis, 59(1), 76-94.

Bristeau, P. J., Callou, F., Vissiere, D., \& Petit, N. (2011). The navigation and control technology inside the ar. drone micro uav. IFAC Proceedings Volumes, 44(1), 1477-1484.

Chester, M. V., \& Horvath, A. (2009). Environmental assessment of passenger transportation should include infrastructure and supply chains. Environmental Research Letters, 4(2)

Choi, Y., \& Schonfeld, P. M. (2017). Optimization of Multi-package Drone Deliveries Considering Battery Capacity, 96th Annual Meeting of the Transportation Research Board, Washington, D.C. (Paper No. 17-05769).

Daganzo, C. F. (2005). Logistics systems analysis. Springer Science \& Business Media.

D'Andrea, R. (2014). Guest editorial can drones deliver?. IEEE Transactions on Automation Science and Engineering, 11(3), 647-648. 
Davis, B., Figliozzi, M. (2013). A methodology to evaluate the competitiveness of electric delivery trucks. Transportation Research Part E: Logistics and Transportation Review, 49(1), 8-23.

Dray, Lynnette. "An analysis of the impact of aircraft lifecycles on aviation emissions mitigation policies." Journal of Air Transport Management 28 (2013): 62-69.

Feng, W., \& Figliozzi, M. (2013). An economic and technological analysis of the key factors affecting the competitiveness of electric commercial vehicles: A case study from the USA market. Transportation Research Part C: Emerging Technologies, 26, 135-145.

Figliozzi, M. (2008). Planning approximations to the average length of vehicle routing problems with varying customer demands and routing constraints. Transportation Research Record: Journal of the Transportation Research Board, (2089), 1-8.

Figliozzi, M., Tucker, C. (2017). What can multicopter drones deliver? A survey and analysis of the capabilities and limitations of state of the art drones, Working paper submitted to the 2018 Transportation Research Board Annual Conference.

Floreano, D., Wood, R. J. (2015). Science, technology and the future of small autonomous drones. Nature, 521(7553), 460-466.

Goodchild, A., Toy, J. (2017). Delivery by drone: An evaluation of unmanned aerial vehicle technology in reducing CO 2 emissions in the delivery service industry. Transportation Research Part D: Transport and Environment.

Hertwich, E. G and Peters, G. P. (2009). Carbon footprint of nations: A global, trade-linked analysis. Environmental science \& technology, 43(16), 6414-6420.

Heutger, M., Kückelhaus, M. (2014). Unmanned Aerial Vehicles in Logistics: A DHL Perspective on Implications and Use for the Logistics Industry.

Horsefly (2017), UPS Tests Residential Delivery Via Drone, [Accessed: August 16, 2017$].$ http://workhorse.com/newsroom/2017/02/ups-tests-residential-delivery-drone

Kim, H. C., Wallington, T. J., Arsenault, R., Bae, C., Ahn, S., \& Lee, J. (2016). Cradle-to-Gate Emissions from a Commercial Electric Vehicle Li-Ion Battery: A Comparative Analysis. Environmental Science \& Technology, 50(14), 7715-7722.

Leishman G. Principles of helicopter aerodynamics. Second edition, Cambridge University Press (2006).

Mathew, N., Smith, S., Waslander, S. (2015). Planning paths for package delivery in heterogeneous multirobot teams. IEEE Transactions on Automation Science and Engineering, 12(4), 1298-1308.

MicroDrones (2017), MD4-3000, https://www.microdrones.com/en/mdaircraft/md4-3000/, [Accessed: June 11, 2016].

Mohammed, F., Idries, A., Mohamed, N., Al-Jaroodi, J., and Jawhar, I. (2014, May). UAVs for smart cities: Opportunities and challenges. In Unmanned Aircraft Systems (ICUAS), 2014 International Conference on (pp. 267-273). IEEE.

Murray, C., Chu, A. (2015). The flying sidekick traveling salesman problem: Optimization of drone-assisted parcel delivery. Transportation Research Part C: Emerging Technologies, 54, 86-109. 
Peters, J. F., Baumann, M., Zimmermann, B., Braun, J., \& Weil, M. (2017). The environmental impact of Li-Ion batteries and the role of key parameters-A review. Renewable and Sustainable Energy Reviews, 67, 491-506.

Renault (2017), Driving range 2017 ZE Kangoo, https://www.renault.co.uk/vehicles/newvehicles/kangoo-ze/driving-range.html [Accessed: August 11, 2017].

Saenz, J., Figliozzi, M., \& Faulin, J. (2016). An assessment of the carbon footprint reductions of tricycle logistics services. Transportation Research Record: Journal of the Transportation Research Board Jan 2016, Vol. 2570, pp. 48-56

Thiels, C. A., Aho, J. M., Zietlow, S. P., and Jenkins, D. H. (2015). Use of unmanned aerial vehicles for medical product transport. Air medical journal,34(2), 104-108.

USDoE, US Department of Energy, "GREET life cycle model," [Online]. Available: https://greet.es.anl.gov/. [Accessed August 10, 2016].

USEPA, US Environmental Protection Agency, "How to use eGRID for Carbon Footprinting Electricity Purcharses in Greenhouse Gas emission inventories," 2016. [Online]. Available: http://www.epa.gov/ttnchie1/conference/ei20/session3/adiem.pdf. [Accessed: August 18, 2016].

USEPA, US Environmental Protection Agency, Greenhouse Gas Emissions from a Typical Passenger Vehicle, 2017. [Online]. Available: ttps://www.epa.gov/greenvehicles/greenhousegas-emissions-typical-passenger-vehicle-0, [Accessed: August 11, 2017].

Wang, X., Poikonen, S., \& Golden, B. (2017). The vehicle routing problem with drones: Several worst-case results. Optimization Letters, 11(4), 679-697. 